\title{
Synthesis, Consolidation and In-Vitro Characterization of Zinc and Potassium Co-Substituted Hydroxyapatite Nano Powders for Bioapplications
}

\author{
Kavitha M \\ \{mk.bio@psgtech.ac.in ${ }^{1}$ \} \\ PSG College of Technology, Coimbatore, India
}

\begin{abstract}
In the present work, the zinc and potassium co-substituted hydroxyapatite powders were successfully prepared by solution combustion synthesis method to study their bioactivity. The existence of functional groups such as phosphate and hydroxyl groups were revealed by FTIR spectroscopy and absorbance at $880 \mathrm{~cm}-1$ confirms the co-substitutions in the synthesized powder. XRD patterns with the peak broadening near 32. showed the presence of HCP phase (hydroxyapatite) with substitutions and nanocrystalline nature. SEM images revealed that the diameter of the synthesized nanorodswas from 10-25 $\mathrm{nm}$ with the length of about 100-400 $\mathrm{nm}$. TEM images also confirmed the partial crystalline nature of the synthesized powders. EDS elemental analysis also confirmed the presence of $\mathrm{Zn}$ and $\mathrm{K}$ in the substitutions along with an average $\mathrm{Ca} / \mathrm{P}$ ratio 1.7 . Porous scaffolds were prepared by gelcasting method. SEM images of consolidated samples showed the presence of nanopores and the in-vitro studies confirmed the bioactivity in simulated body fluid without any cytotoxicity. Thus, the above results confirmed that the synthesized powders have similar characteristics like human bone and suggested for using it as a material for preparing porous scaffolds for bone, dental repairs, and replacements.
\end{abstract}

Keywords: Co-substitutions, nano-hydroxyapatite, cytotoxicity, dissolution studies.

\section{Introduction}

Bioactivity of Hydroxyapatite (HA) plays a vital role in the medical field in applications such as orthopedic and dental repairs and replacements. Bone defects caused by diseases or genetic disorders are a challenge for the normal functioning of a human and needs autografting, a 'gold standard' for bone re- generation Lim (2019)- García-Gareta (2015). Fracture fragments may disrupt the blood supply for the sequential activation of cells and bioactive molecules that are responsible for the fracture healing process K (2015), Szcze $\AA \dot{Z}$ (2017). The migration and recruitment of osteo progenitor cells, followed by their proliferation, are the first steps in bone tissue engineering followed by differentiation, matrix formation along with remodeling of the bones Gong (2015), Kim (2015). The osteoconductive, osteogenic, osteoinductive, and osteopromotive characteristics of grafts determine their capacity to promote recovery $\mathrm{K}$ (2015). In the structure of natural apatite, different metal ions such as $\mathrm{K}+\mathrm{Mg} 2+, \mathrm{Sr} 2+, \mathrm{Zn} 2+$ or $\mathrm{Mn} 2+$ are the most important trace elements and found in human bones and plasma. $\mathrm{Zn}$ is the second most frequently found transi- tion metal after iron in the human body and responsible for collagen synthesis, preserve 
bone mineral density, bone metabolism and avoid diseases like osteo- porosis and arthritis. Potassium substitutions in the bone mineral reduce the calcium excretion. Hydroxyapatite with chemical formula $\mathrm{Ca}_{10}\left(\mathrm{Po}_{4}\right)_{6}(\mathrm{OH})_{2}$ is a well-known bioceramic material with outstanding bioactivity and appropriate for constructing orthopedic and dental substitutes. The presence of larger amount of hydroxyapatite promotes the differentiation and mineralization of MC3T3E1 cells on the composite scaffolds. Kavitha (2014), Rao (2016). Zinc is a trace element required for normal mammalian cell functions such as DNA and protein synthesis. It is used in osteoblastic cells to stimulate cell proliferation and alkaline phosphatase activity, which improves the osteogenic impact. Roohani (2013)- Seo (2010). This reduces bone resorption in MC3T3- E1 cells. Potassium lowers the excretion of urine calcium and improves calcium balance in healthy people Ceglia (2009), Dawson-Hughes (2009). Potassium bi- carbonate and potassium citrate reduce the calcium excretion levels to a greater extent than potassium chloride Lambert (2015).

Substitution of zinc along with potassium in HA is recommended for their contribution in neutralizing the bone depleting metabolic acids to greater os- teogenic activity and better calcium stability in bones. The presence of both the elements in the hydroxyapatite scaffold tends to increase the osteoblas- tic activity during bone regeneration. Though many research works on $\mathrm{Zn}$ substitution and $\mathrm{K}$ substitution in hydroxyapatite are reported, reports on cosubstitution of $\mathrm{Zn}$ and $\mathrm{K}$ in hydroxyapatite are rarely found. Hence, an at- tempt on the preparation of zinc and potassium co-substituted hydroxyapatite powders were done and their characteristics are studied in the present work.

Preparation of substituted hydroxyapatite powders can be done through combustion method Rao (2016), Kaygili (2018), hydrolysis, sol-gel Ching (2015), hydrothermal Moussa (2018), Nouri-Felekori (2019), inverse mi- croemulsion method Li (2017), Ma (2016), sonochemical SzczeÅŻ (2017), Qi

(2016), chemical precipitation Ching (2015), Gentile (2015), solid-state re- action method Monmaturapoj and Yatongchai (2010). Out of these above- mentioned methods, considering the rapid synthesis with good energy effi- ciency to produce partially crystalline co-substituted HA powders, a self- propagating high-temperature combustion synthesis method is preferred. The aim of this work is to prepare the zinc and potassium co-substituted hy- droxyapatite powders using solution combustion synthesis method along with characterization and consolidation of powders to ensure their purity, phases present and its bioactivity, to ensure its properties for bio applications.

\section{Materials And Methods}

Materials used for the synthesis of zinc and potassium co-substituted hy- droxyapatite are commercially pure, SD Fine Chem Ltd make, calcium ni- trate tetrahydrate (mol.wt: 164.09 $\mathrm{g} / \mathrm{mol}$ ), zinc chloride (mol.wt: $136.286 \mathrm{~g} / \mathrm{mol}$ ), potassium carbonate (mol.wt: $138.21 \mathrm{~g} / \mathrm{mol}$ ), diammonium hydrogen orthophosphate (anhydrous, mol.wt: $132.06 \mathrm{~g} / \mathrm{mol}$ ) and urea (mol.wt: $60.06 \mathrm{~g} / \mathrm{mol}$ ). Double distilled water was used for the preparation of the HA pow- ders.

- Powder synthesis

A self-propagating combustion synthesis technique was used to produce the cosubstituted HA powders. The containers required to prepare the solution were properly washed with double distilled water to avoid contamination. One molar concentration solutions of 
calcium nitrate tetrahydrate, zinc chloride, and potassium carbonate were thoroughly mixed using magnetic stirrer for 30 minutes. Then, $150 \mathrm{ml}$ of diammonium hydrogen orthophosphate solution was added dropwise to the above solution and stirred well to achieve homogeneity. Finally, a stoichiometric amount of urea was added as fuel into this solution, just before transferring into the muffle furnace, maintained at $400 \mathrm{oC}$. At this temperature, urea decomposed into isocyanic acid (HNCO) and ammonia $\left(\mathrm{NH}_{3}\right)$ gaseous mixture. This exothermic reaction leads to a localized rise in temperature within the solution. This spontaneous rise in temperature leads to the combustion of the added precursors to form zinc and potassium co- substituted HA porous mass in a single step. Three samples were prepared with a different soaking time of 15,30 and 45 minutes, to check the optimum time required for complete combustion of the precursors to get $\mathrm{Zn}$ and $\mathrm{K}$ co- substituted HA powder without any impurities. Then, the porous mass was crushed using mortar and pestle, washed using acetone and then dried.

\section{- Consolidation of powder}

Consolidation of the synthesized powders was done using the gel casting method. The consolidation initially involves the preparation of slip containing the synthesized powder, double distilled water, and organic monomer solution. Generally, polyacrylic acids such as Versicol KA11 and Dispex A40 (Allied colloids, UK) were used as dispersing agents for hydroxyapatite powders. Homogenization was done by using polyethylene spatula and then agitated with single blade stirrer. This slip was then poured into the thermocol molds having the required die cavity. The aqueous solution of acrylate monomers containing dienes was used to set the slip solution by enhancing the cross- linking to produce three-dimensional networking of solid particles. After polymerization, the gels were carefully removed from the mold after $20 \mathrm{hrs}$. It is then further dried at $300 \circ \mathrm{C}$ for 90 minutes. The dissolution characteristics of the prepared samples were done in simulated body fluid prepared with specified amount of $\mathrm{NaCl}, \mathrm{NaHCO}_{3}, \mathrm{HCl}$, and $\mathrm{MgCl}_{2}$.

\section{Results And Discussion}

Structure and properties of synthesized $\mathrm{Zn}$ and $\mathrm{K}$ co-substituted hydroxyap- atite powders were analyzed using XRD, FTIR spectroscopy and SEM/EDS. Then the as-synthesized powders were consolidated to $25 \mathrm{~mm}$ cubes to study their metallurgical and biological characteristics in simulated body fluid (SBF).

- $\quad$ FTIR spectroscopy

Fourier Transform Infra Red spectroscopy was used for analyzing the functional groups present in the samples synthesized with 15,30 and $45 \mathrm{~min}$.

Fig.1. FTIR spectra image for three samples

Spectra of all the three samples (Figure 1) showed small absorption at 470, 478, 462 $\mathrm{cm}-1$ which are attributed to the v2 vibration mode and sharp bands at $570,563,609 \mathrm{~cm}-1$ were due to the $\mathrm{v} 4$ bending vibrations of phosphates without adsorbed carbonates. Absorbance around $880 \mathrm{~cm}-1$ indicated the substitutions in the cationic positions which might have confirmed $\mathrm{Zn}$ and $\mathrm{K}$ substitution in Ca positions of HA. The appearance of strong bands at 1026 and $1095 \mathrm{~cm}-1$ in HA-45 and 1002 and $1103 \mathrm{~cm}-1$ in HA-30 and 1018 and $1103 \mathrm{~cm}-1$ samples respectively can be v3 stretching of $\mathrm{PO}_{4} 3-$ ions. Small bands at $1427 \mathrm{~cm}-1,1411$ $\mathrm{cm}-1,1442 \mathrm{~cm}-1$ in HA-15, HA-30, HA-45 respectively and $1489 \mathrm{~cm}-1$ indicate the v3 
stretching mode due to the presence of phosphates. The smaller peaks around $1643 \mathrm{~cm}-1$ and $2360 \mathrm{~cm}-1$ were characteristic peaks of $\mathrm{H}_{2} \mathrm{O}$. A moderately broad peak around $3495 \mathrm{~cm}-1$ in all samples can be attributed to hydrated $\mathrm{OH}-$ ions. A sharp peak at $3556 \mathrm{~cm}^{-1}$ and small disturbances around $3865 \mathrm{~cm}-1$ may probably be due to

the stretching vibrations of $\mathrm{OH}$-in HA powders, whereas the variation in peak intensities was due to the removal of $\mathrm{OH}$ ions when the soaking time increases from 15 min to $45 \mathrm{~min}$. Thus the results confirmed the co-substitutions ( $\mathrm{Zn}$ and $\mathrm{K}$ ) in synthesized hydroxyapatite powders.

\section{- XRD analysis}

SHIMADZU Lab X-6000 X-Ray Diffractometer was used to carry out the XRD analysis for obtaining the diffraction pattern of the prepared samples using Copper $(\mathrm{K} \alpha)$ radiation $(\lambda=$ $1.5406 \AA$ ) with a scan speed of $2 \% / \mathrm{min}$. Figure 2 shows the XRD patterns of all the three samples having different synthesis times 15,30 and $45 \mathrm{~min}$.

Fig.2. XRD spectrum for three samples

The crystal structure, phases present, change in lattice parameters and crystallite sizes of all the three samples were determined from XRD reports. XRD patterns of the prepared samples are closely matching with those of standard JCPDS file of pure hydroxyapatite (09432). The most intense peaks was observed at around 31.82 in $15 \mathrm{~min}$ sample and $32.01^{\circ}$ in 45 min sample. Presence of nearby three peaks confirmed the HCP crystal structure while and a hump near $32^{\circ}$ due to the peak broadening confirmed the nano crystalline nature of the synthesized HA powders. The peak shift from most intense peak of pure HA indicates the substitution of smaller Zn atom $(139 \mathrm{pm})$ and larger K atom $(280 \mathrm{pm})$ in Ca positions (231 $\mathrm{pm})$. The crystallite sizes were calculated using Debye Scherrer equation given below and listed in the Table 1.

\section{$\mathbf{D}=\mathbf{K} \lambda /(\beta \cos \theta)$}

Where $\mathrm{D}$ is the average thickness in vertical direction of the crystal, $\mathrm{K}$ is Scherrer constant equal to $0.89, \lambda$ is the wavelength of $\mathrm{X}$-ray, $\beta$ is integral height to width of the diffraction peak (FMHM), $\theta$ is diffraction angle.

[Table 1 about here.]

The crystallite size of all the three samples were from $17 \mathrm{~nm}$ to $25 \mathrm{~nm}$. It was observed that an increase in synthesis time led to the increase in the crystallite size. The increased Bragg peak intensities and narrower peak widths indicated an increase in the degree of crystallinity of the synthesized powders from $15 \mathrm{~min}$ to $45 \mathrm{~min}$. The \% crystallinity was calculated from the variation in intensities of the XRD peaks and reported in Table 1. Crystallite size and \% crystallinity increased with increase in synthesis time. When thecrystallite size increases, grain boundary area decreases, thus increasing the \% crystallinity. The calculated lattice parameter values are also listed in Table 1 and indicates that there is shrinkage in both ' $c$ ' and ' $a$ ' lattice site due to thenegative lattice strain. This shows that the effect of smaller $\mathrm{Zn}$ atom substitution in the lattice is higher than the larger $\mathrm{K}$ atom and lead to the hypothesis that the $\mathrm{Zn}$ atoms may occupy the body centres or corners of the HCP structure to have much effect in change in lattice constants. This leads to compressive residual stresses in the material, which is desirable property for the HA powders. XRD results confirm that the combustion method may be used for synthesize of co-substituted HA powders in a single step.

- $\mathrm{SEM} / \mathrm{EDS}$ analysis 
The morphology and particle size of the synthesized samples were examined using Scanning Electron Microscopy (SEM) of make JEOL-JSM 6360. SEM images shown in Figure 3 to 5 of the synthesized hydroxyapatite powders showed agglomerates of particles with dimensions from $250 \mathrm{~nm}$ to $1000 \mathrm{~nm}$.

High-resolution images revealed nanorod like morphology with 10-25 nm diameter with length 100-400 nm. This confirms the results determined from XRD reports. Agglomeration and its sizes increases with increasing synthesis time from 15 to $45 \mathrm{~min}$, may be due to clustering and further sintering of nanorods when there is enough exothermic heat. The aspect ratio of the nanorods was found to be in the range $10-15$, which is similar to the morphological characteristics of human bone mineral and substitution of $\mathrm{Zn}$ and $\mathrm{K}$ does not have affected the morphology of HA from the previous reports Kavitha (2014). The absorbability/bioactivity of HA in body fluid during patient recovery process in implant applications depend on this aspect ratio. It seems that the variation in synthesis time has very less influence on the final morphology of the nanorods. However, the effect of time is high on agglomeration characteristics of HA powders. Figure 6 (a) and (b) showed the TEM images of the $15 \mathrm{~min}$ and $45 \mathrm{~min}$ samples. The images showed the partial crystalline nature of the nanorods and increase in crystallinity in 45 min sample than in 15 min sample.

Min sample (b 45 min sample

This confirms the results obtained from XRD reports and SEM images. The interplanar distance ' $d$ ' for 15 min sample was determined as $2.7598 \AA$ which corresponds to (211), where there is a slight decrease in ' $d$ ' value from the pure hydroxyapatite (2.81 $\AA$ ). Elemental analysis (EDS) were performed in order to determine the elements present in the prepared samples.

Figure 3 and 5 right side top images indicate the EDS spectrum for the 15 and $45 \mathrm{~min}$ sam- ples respectively. $\mathrm{Ca} / \mathrm{P}$ ratio in the synthesized powders were observed from

1.59 - 1.86. Presence of $\mathrm{Zn}$ and K peaks in the EDS report confirmed the sub- stitution of both the elements along with $\mathrm{Ca}$ and $\mathrm{P}$ in the synthesized powder. The confirms the complete combustion, diffusion, and redistribution of substi- tutional atoms into the solvent matrix. This also confirms that the solution combustion technique may be used forbulk production of hydroxyapatite in an energy-efficient and cost-effective way with less synthesis time of 15 $\min$.

4.5 Characteristics of consolidated scaffold samples

15 min sample was selected for consolidationto form a scaffold andthe prepared scaffolds were analyzed using SEM/EDS, dissolution and cytotoxicity test to conform their bonding and biological characteristics. Visual observation of the consolidated scaffolds exhibited white, smooth, non-sticky and porous part without any cracks. The shrinkage after drying was determined as $16 \%$ due to the evaporation of liquid medium and binders added during gel casting.

Figure 7 shows the SEM image of 15 min consolidated scaffold before dis- solution studies indicating flat surface with irregular nanopores with pore size ranging from $40 \mathrm{~nm}-$ $200 \mathrm{~nm}$. Porous HA parts are preferred for orthopedic applications since the pores provide mechanical interlocking between particles and allow the body fluid to pass through capillary action into the implants. This enhances the dissolution of $\mathrm{Ca}, \mathrm{P}, \mathrm{Zn}, \mathrm{K}$ ions leading to 
supersaturation and re-deposition of calcium phosphates inside the pores. Bone tissue grows well into the pores ensuring strong bonding leading to firm fixation of the im- plants to the natural bone leading to fast recovery. The porosity aids in tissue growth and their binding with the HA and this may be confirmed further with dissolution studies.

\subsubsection{In-vitro Analysis}

Figure8 shows the SEM image of the 15 min scaffold after dipping in the $50 \mathrm{ml}$ of prepared SBF solution.

SEM images revealed the change in surface morphology of the consolidated sample after soaking in the SBF solution. The scaffold is firm in the SBF solution and also the $\mathrm{pH}$ is maintained at 7 during the dissolution studies. Table 2 shows the results obtained during dissolution studies.

Initial decrease in $\mathrm{pH}$ is due to the presence of $\mathrm{OH}$ group in scaffold and the basic buffer added during SBF preparation takes 40 hours to infiltrate into the porous hydroxyapatite and neutralize the scaffold. Consistent $\mathrm{pH}$ after two days shows that the scaffold gets adjusted with the SBF environment and it can be used as implants for orthopedic applications. It is concluded that the prepared scaffold stays as such for about 7days and the $\mathrm{pH}$ also have been neutral, in which there also a monolayer deposition of calcium and phosphate layer over the surface. The increase of weight from $2.02 \mathrm{~g}$ to $4.48 \mathrm{~g}$ as shown in Table 2. Figure9 shows the results of the cell culture over the prepared samples.

Cytotoxicity study showed that the IC 90 value for the prepared ceramic scaffolds is $27 \mu \mathrm{g} / \mathrm{ml}$. Hence it is concluded that the prepared samples are non- toxic and may be taken for further studies for orthopedic applications. Studies are also being performed in order to incorporate biopolymers in these porous scaffolds to improve their properties.

\section{CONCLUSION}

Zinc and potassium substituted hydroxyapatite was successfully synthesized using combustion synthesis method in a single step. FTIR results confirmed the presence of functional groups, while XRD and EDS analysis confirmed the substitution of $\mathrm{Zn}$ and $\mathrm{K}$ in the synthesized powders. XRD reports of $45 \mathrm{~min}$ sample qualitatively confirmed high purity and better crystallinity than 15 - and 30-min samples. The calculated crystallite size of all the three powders was about $17 \mathrm{~nm}-25 \mathrm{~nm}$ with the \% crystallinity of 51-67\%. SEM images showed that the diameter of the synthesized nanorods was from 10- $25 \mathrm{~nm}$ with the length of about 100-400 $\mathrm{nm}$. EDS Elemental analysis also confirmed the presence of $\mathrm{Zn}$ and $\mathrm{K}$ in the substitutions along with an average $\mathrm{Ca} / \mathrm{P}$ ratio 1.7 . SEM images of the scaffolds prepared by gel casting revealed nanopore structures that pave the way for the growth of bone tissues in it. The dissolution studies showed that the weight of the scaffold increased by the deposition of calcium and phosphate layers from the simulated body fluid. The cytotoxicity test also revealed that the IC 90 value is $27 \mu \mathrm{g}$ and it is $100 \%$ non-toxic. Consolidated samples revealed the presence of nanopores and also confirmed that deposition/bioactivity in simulated body fluid without any cytotoxicity. Thus, the above results confirmed that the synthesized powders have similar characteristics like natural bone mineral and can be taken for further studies to use it in drug delivery system. 


\section{References}

[1] Ceglia L (2009) Potassium bicarbonate attenuates the urinary nitrogen ex- cretion that accompanies an increase in dietary protein and may promote calcium absorption. Journal of Clinical Endocrinology and Metabolism 94(2) Ching CY (2015) Characteristics and properties of hydoxyapatite derived by sol-gel and wet chemical precipitation methods. Ceramics International

[2] 41(9)

[3] Dawson-Hughes B (2009) Treatment with potassium bicarbonate lowers cal- cium excretion and bone resorption in older men and women. Journal of Clinical Endocrinology and Metabolism 94(1)

[4] García-Gareta E (2015) Osteoinduction of bone grafting materials for bone repair and regeneration. Bone 81

[5] Gentile P (2015) Process optimization to control the physicochemical charac- teristics of biomimetic nanoscale hydroxyapatites prepared using wet chem- ical precipitation. Materials 8(5) Gong T (2015)

[6] K E (2015) Bone grafting: Sourcing, timing, strategies, and alternatives. Journal of Orthopaedic Trauma 29(12)

[7] Kavitha M (2014) Solution combustion synthesis and characterization of strontium substituted hydroxyapatite nanocrystals. Powder Technology Kaygili O (2018) Characterization of Mgcontaining hydroxyapatites synthe-sized by combustion method. Physica B: Condensed Matter $537(3)$

[8] Kim HL (2015) Preparation and characterization of nano-sized hydroxyap- atite/alginate/chitosan composite scaffolds for bone tissue engineering. Ma- terials Science and Engineering C 54

[9] D. S. Vijayan, A. Mohan, J. J. Daniel, V. Gokulnath, B. Saravanan, and P. D. Kumar, "Experimental Investigation on the Ecofriendly External Wrapping of Glass Fiber Reinforced Polymer in Concrete Columns," vol. 2021, 2021.

[10] Lambert H (2015) The effect of supplementation with alkaline potassium salts on bone metabolism: a meta-analysis. Osteoporosis International 26(4)

[11] Li W (2017) Preparation of $\mathrm{CaP} / \mathrm{pDNA}$ nanoparticles by reverse microemul- sion method: Optimization of formulation variables using experimental de- sign. Asian Journal of Pharmaceutical Sciences 12(2)

[12] Lim ZXH (2019) Autologous bone marrow clot as an alternative to autograft for bone defect healing. Bone \& Joint Research 8(3)

[13] Ma X (2016) Controllable synthesis of spherical hydroxyapatite nanoparticles using inverse microemulsion method. Materials Chemistry and Physics 183 Monmaturapoj N, Yatongchai C (2010) Effect of Sintering on Microstructure and Properties of Hydroxyapatite Produced by Different Synthesizing Methods. Journal of Metals, Materials and Minerals 20(2)

[14] Moussa SB (2018) Combined effect of magnesium and amino glutamic acid on the structure of hydroxyapatite prepared by hydrothermal method. Materials Chemistry and Physics 212

[15] Nouri-Felekori M (2019) Synthesis and characterization of $\mathrm{Mg}, \mathrm{Zn}$ and Sr- incorporated hydroxyapatite whiskers by hydrothermal method. Materials Letters 243

[16] Qi C (2016) Sonochemical synthesis of hydroxyapatite nanoflowers using creatine phosphate disodium salt as an organic phosphorus source and their application in protein adsorption. RSC Advances 6(12)

[17] Rao RR (2016) Development of microporous scaffolds through slip casting of solution combustion derived nano-hydroxyapatite. InterCeram: Interna- tional Ceramic Review 65(3)

[18] Roohani N (2013) Zinc and Its Importance for Human Health: An Integrated Review. Journal of Research in Medical Sciences pp 1-27

[19] Seo HJ (2010) Zinc may increase bone formation through stimulating cell pro- liferation, alkaline phosphatase activity and collagen synthesis in osteoblas- tic MC3T3-E1 cells. Nutrition Research and Practice 4(5)

[20] SzczeÅŻ A (2017) Synthesis of hydroxyapatite for biomedical applications. Advances in Colloid and Interface Science 249 
Fig. 1 SEM and EDS images for 15 min sample

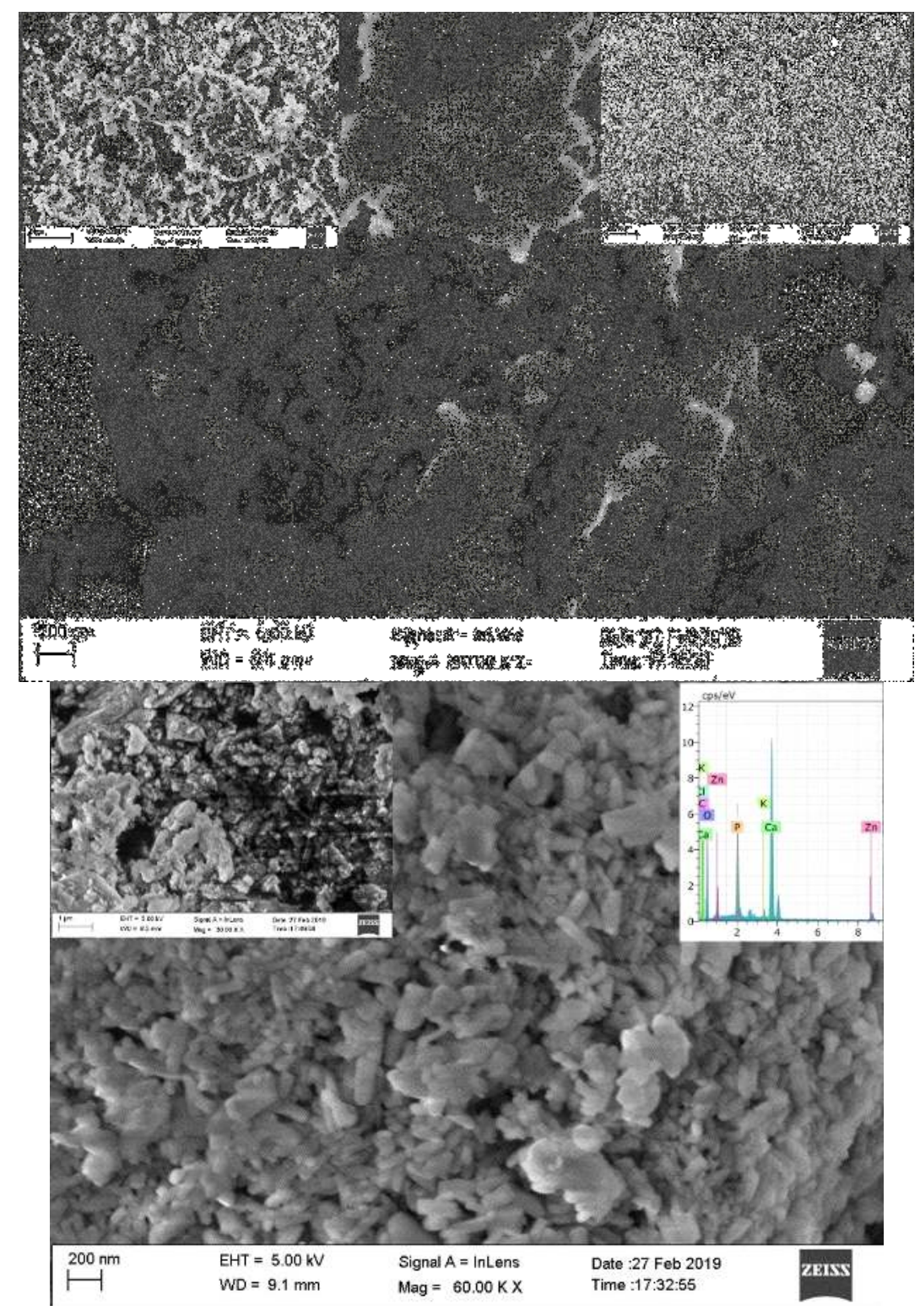

Fig. 2 SEM and EDS images for 30 min sample 


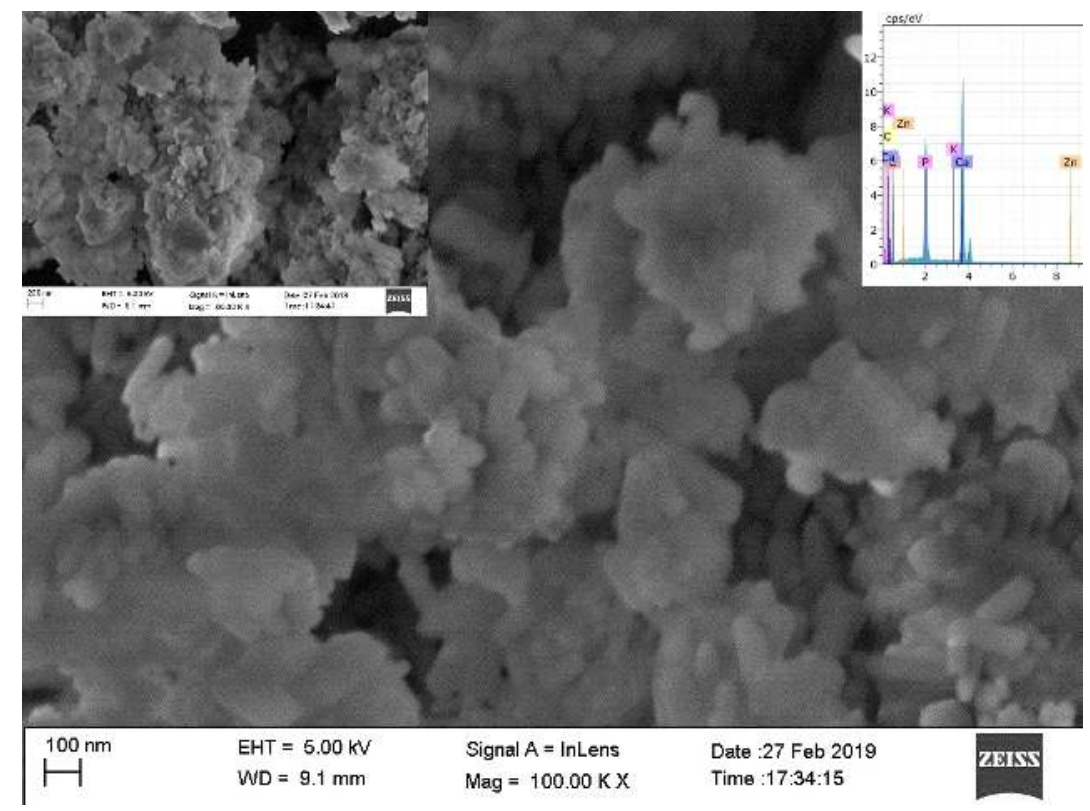

Fig. 3 SEM and EDS images for 45 min sample

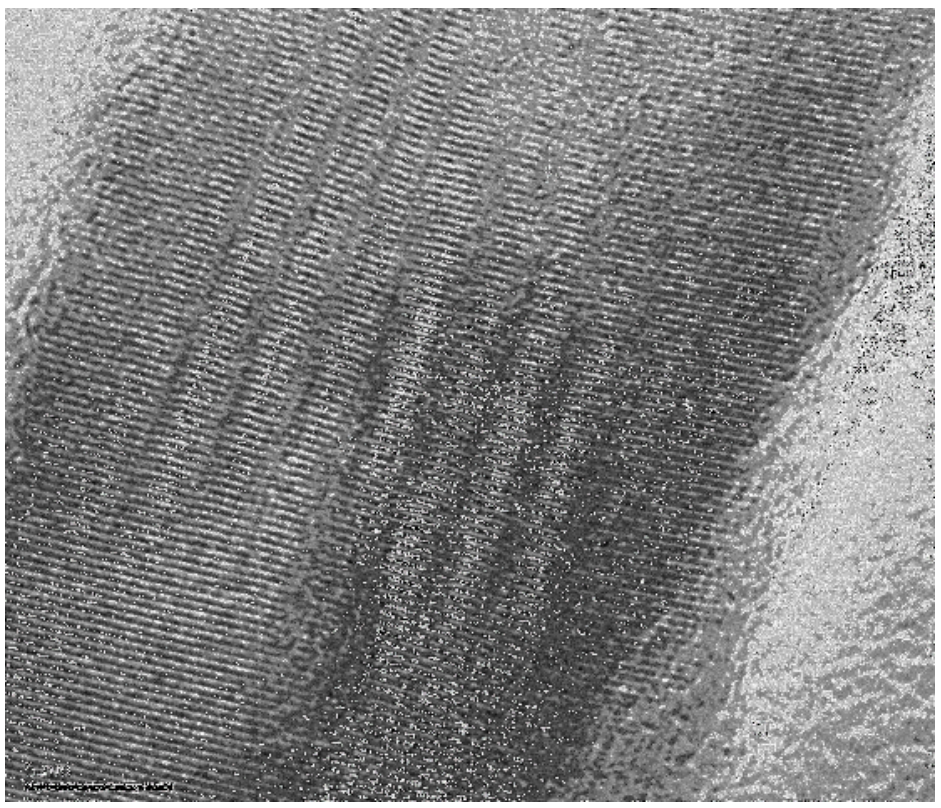

Fig. 4 


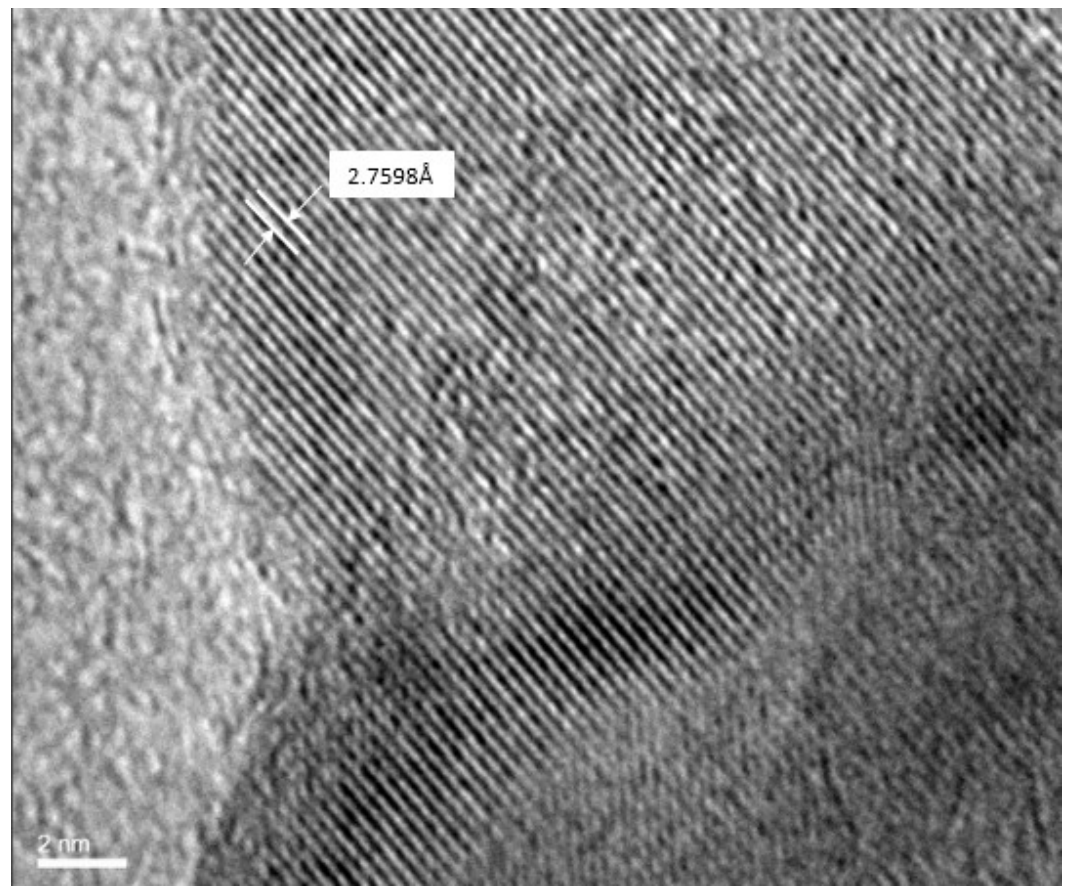

Fig. 5 TEM images of 15 and 45 min HA samples

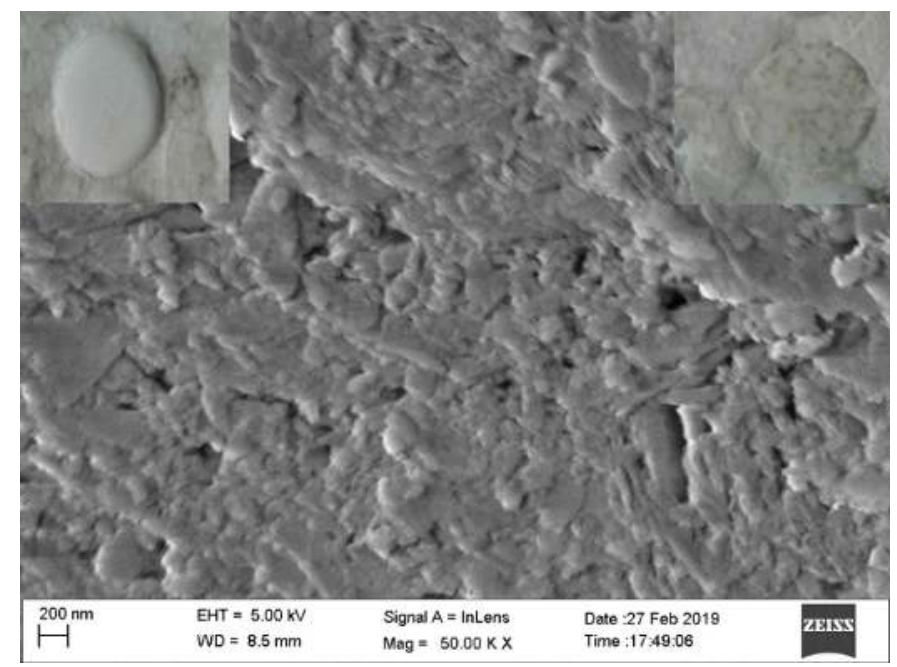

Fig. 6 SEM image of 15 min consolidated scaffold before dissolution studies 


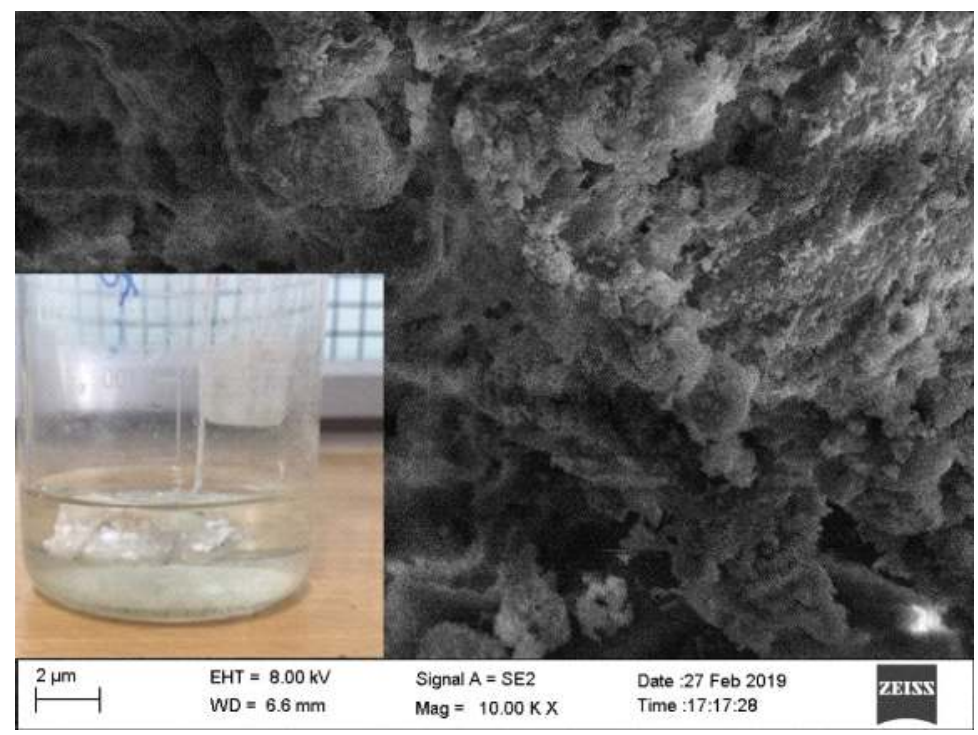

Fig. 7 SEM image of 15 min consolidated scaffold after dissolution studies

Table 1 esults obtained from XRD reports of 15,30 and 45 minHA samples

\begin{tabular}{|c|c|c|c|c|}
\hline \multirow[t]{2}{*}{$\begin{array}{l}\text { Sample ID (based } \\
\text { on soaking time) }\end{array}$} & \multirow[t]{2}{*}{$\begin{array}{l}\text { Crystallite } \\
\text { size (nm) }\end{array}$} & \multirow[t]{2}{*}{$\begin{array}{c}\text { Degree of } \\
\text { crystallinity }\end{array}$} & $\begin{array}{c}\text { Lattice } \\
\text { con- } \\
\text { stanta }\end{array}$ & \multirow[t]{2}{*}{$\begin{array}{c}\text { Lattice } \\
\text { strain }(\AA)\end{array}$} \\
\hline & & & $\begin{array}{c}\text { and } \quad c \\
\text { values } \\
\left(\mathbf{A}^{\circ}\right)\end{array}$ & \\
\hline $15 \mathrm{~min}$ & 17.1047 & $51 \%$ & 8.89036 .8847 & -52.7 \\
\hline $30 \mathrm{~min}$ & 19.4399 & $54 \%$ & 8.24936 .7939 & -45.09 \\
\hline $45 \mathrm{~min}$ & 25.0758 & $67 \%$ & 8.22866 .8328 & -42.40 \\
\hline
\end{tabular}

Table 2 hange in weight and $\mathrm{pH}$ duringthe dissolution test in SBF

\begin{tabular}{ccccc}
\hline $\begin{array}{c}\text { Time of } \\
\text { soaking (hours) } \\
\text { Initial }\end{array}$ & $\begin{array}{c}\text { Change } \\
\text { in pH }\end{array}$ & $\begin{array}{c}\text { Weight of the } \\
\text { specimen }(\mathrm{g})\end{array}$ & $\begin{array}{c}\text { Change in } \\
\text { weight }(\mathrm{g})\end{array}$ & $\begin{array}{c}\text { Cumulative CaP } \\
\text { deposited }\end{array}$ \\
24 & 2 & 2.02 & - & - \\
48 & 2.5 & 2.06 & 0.04 & 0.04 \\
64 & 7 & 2.75 & 0.69 & 0.73 \\
112 & 7 & 3.18 & 0.43 & 1.16 \\
136 & 7 & 3.86 & 0.68 & 1.84 \\
160 & 7 & 4.34 & 0.48 & 2.32 \\
184 & 7 & 4.36 & 0.02 & 2.34 \\
\hline
\end{tabular}

